\title{
Religious Conversion in Colonial Africa
}

\section{Citation}

Nunn, Nathan. 2010. "Religious Conversion in Colonial Africa." American Economic Review 100 (2) (May): 147-152. doi:10.1257/aer.100.2.147. http://dx.doi.org/10.1257/aer.100.2.147.

\section{Published Version}

doi:10.1257/aer.100.2.147

\section{Permanent link}

http://nrs.harvard.edu/urn-3:HUL.InstRepos:11986328

\section{Terms of Use}

This article was downloaded from Harvard University's DASH repository, and is made available under the terms and conditions applicable to Other Posted Material, as set forth at http:// nrs.harvard.edu/urn-3:HUL.InstRepos:dash.current.terms-of-use\#LAA

\section{Share Your Story}

The Harvard community has made this article openly available.

Please share how this access benefits you. Submit a story.

Accessibility 


\title{
Religious Conversion in Colonial Africa
}

\author{
By NATHAN NUNN
}

Within economics, there has been a recent effort to better understand the notion of culture, typically defined as beliefs, values, and norms held by individuals. Empirical work has focused on identifying systematic cultural differences between individuals from different ethnic and national backgrounds. More recently, attention has turned to the historical origins of cultural differences (e.g., Luigi Guiso, Paolo Sapienza, and Luigi Zingales 2008; Nathan Nunn and Leonard Wantchekon 2009).

Colonial Africa provides a natural laboratory to examine how an external intervention can have lasting impacts on people's beliefs and values. This study examines the effect of European missionary activities in colonial Africa on the subsequent evolution of culture, as measured by religious beliefs. The empirical results show that descendants of ethnic groups that experienced greater missionary contact are today more likely to self-identify as Christian. This correlation provides evidence that foreign missionaries altered the religious beliefs of Africans, and that these beliefs persist as they are passed on from parents to children. Put differently, the results show that historic events can have a lasting impact on culture.

The findings also provide rare empirical evidence of the historical determinants of longrun religious conversion. Studies of conversion typically focus on contemporary determinants (see Jason Hwang and Robert Barro 2007 and the references therein). Although a number of studies have examined the long-term impacts of missionary activities, they have not considered their long-run impacts on religious beliefs and values (e.g., Robert D. Woodberry 2004). One of the few papers that consider a historical determinant of long-run conversion is by Murat

\footnotetext{
* Department of Economics, Harvard University, 1805 Cambridge Street, Cambridge, MA 02138 (e-mail: nnunn@ fas.harvard.edu). Also affiliated with the NBER and BREAD. I thank Robert Barro, Oeindrila Dube, Rachel McCleary, and Robert Woodberry for valuable comments, as well as Sayon Deb for excellent research assistance.
}

Iyigun (2008), which provides evidence linking the Protestant Reformation to the sixteenthcentury expansion of the Ottoman Empire into continental Europe.

\section{Historical Background}

In the late nineteenth and early twentieth centuries, Africa witnessed an explosion of missionary activity. The success of missionaries during this period was due in large part to the onset of colonial rule, which made clear to Africans the benefit of European education. Robin Horton writes: "With the advent of the twentieth century ... Europeans came to be seen as symbols of power, and Christianity itself came to be seen as part of a larger order, comprising Western education, colonial administration, commerce and industry, with which everyone had henceforth to reckon. These changes created a much more favorable climate for conversion." (Horton 1971, 86). The provision of education soon became the main reward used by missionaries to lure Africans into the Christian sphere, and so much so that even by the late colonial period, nearly all education was still provided by missionaries. [1]

The decision of where to locate foreign mission stations is of central importance for the empirical analysis. A number of factors played a role in determining a mission's location. Among the most important were access to a clean water supply, the ability to import supplies from Europe, and an abundance of fertile soil that could be used to grow crops (Hildegard Binder Johnson 1967). The locations of missions also exhibited a form of path dependence. The routes of initial missionary explorers determined which parts of Africa were the most well-known

\footnotetext{
${ }^{1}$ For example, in the 1940 s, 97 percent of the student population in Ghana and Nigeria were from missionary schools. In South Africa during this period, there were 5,360 mission-sponsored schools and only 230 statesponsored schools. See Edward H. Berman $(1974,527)$ for details.
} 
to Europeans, as well as the locations of the earliest mission stations. From these first stations, larger networks of stations, that together formed a series of trans-shipment points from the coast to the interior were developed. By creating these networks, missionaries could penetrate deep into the interior while maintaining access to supplies from Europe. The colonial railway network also provided an additional means of remaining connected with Europe, and therefore was another factor that affected mission locations. The final factor of importance was the slave trade. Missionaries sought to bring an end to the slave trade within Africa, and thus a concerted effort was made to locate mission stations in areas where slavery was prevalent (Johnson 1967).

In the analysis, I am careful to control for these potential determinants of the locations of mission stations. If these factors have an independent impact on long-term conversion, then not properly accounting for them will bias the estimates of interest.

\section{Data and Their Sources}

Information on the current religion of individuals is from the 2005 round of the Afrobarometer surveys, which cover approximately 21,000 nationally representative individuals from 17 sub-Saharan African countries. Because I am interested in identifying conversions from indigenous religions to Christianity, I omit from the sample anyone that is not of African descent. The surveys also collect information on a host of additional individual-level characteristics, including education, occupation, quality of living conditions, and the population density of the respondent's neighborhood, which are included as control variables in the analysis.

To construct measures of the historic influence of Catholic and Protestant missionaries within Africa, I use information from a map published by William R. M. Roome (1924). The map provides the precise location of all foreign mission stations in Africa at the time. The map also provides information on the location of British and Foreign Bible Society (BFBS)

\footnotetext{
${ }^{2}$ Roome, William R. M. 1924. "Ethnographic Survey of Africa: Showing the Tribes and Languages; also the Stations of Missionary Societies [map]."
}

Bible depots, as well as the African languages the Bible had been translated into.

The historic information on the locations of foreign missions is then linked to the Afrobarometer survey data. My interest is in determining whether the descendants of those exposed to foreign missionaries today hold different beliefs as a result of this. Therefore, ideally we would like an individual-specific measure that quantifies the exposure of each person's ancestors to Christianity. Although we do not have the necessary information for this, we are able to construct an ethnicity-level measure of historic exposure. Based on individuals' self-reported ethnicities, available from the Afrobarometer surveys, we know the exposure of his or her ancestors to missionaries (using the exposure of his or her ethnic group as a proxy). The measure is constructed using the spatial distribution of ethnic groups in the nineteenth century, which is from George P. Murdock (1959). For each ethnicity, I calculate the number of missions (per 1,000 square kilometers) on land historically inhabited by the group. ${ }^{3}$ I use this as the measure of historic exposure of a respondent's ancestors to missionary activity.

Because I am interested in identifying the effect of missionary activities working through the transmission of religious values from parents to children, there is concern that any relationship between the ethnicity-level measure and religion today may occur through other channels. For example, in many of the mission stations, permanent stone structures (churches, boarding schools, hospitals, etc.) were eventually constructed, and many of these still exist today. The continued existence of these structures may have a positive effect on current conversion, or continued adherence to Christianity, biasing the estimates of interest. To account for this potential effect of missions, I construct an additional location-specific measure of the historic presence of mission stations. The measure is constructed by first identifying a 25-kilometer radius around the current location of respondents within the Afrobarometer survey. I then calculate the number of missions historically located

\footnotetext{
${ }^{3}$ Because the measure is left skewed, I take the natural $\log$ of one plus the normalized number of missions. The results are not sensitive to this specific parameterization.

${ }^{4}$ In total there are approximately 850 ethnic groups. Of these, 185 are present in the Afrobarometer surveys.
} 
within this radius. This provides a measure of the historic presence of mission stations in the respondent's current location. By controlling for this variable, I am able to account for impacts of missions that occur through location-specific factors, such as public goods, institutions, and broader social structures.

In the analysis, I also control for the determinants of the location of mission stations discussed in the previous section. Using information on the historic locations of railway lines and of explorer routes, I construct ethnicity- and village-level indicator variables that equal one if an ethnic group or village contacted a pre-colonial European explorer or was integrated into the colonial railway network. Using data on soil suitability and water sources, I construct ethnicity- and village-level measures of the fraction of land that is suitable for cultivation, and the fraction of land that is within ten kilometers of a water source. The final control variables, taken from Nunn and Wantchekon's (2009) paper, measure the intensity of the slave trade across villages and ethnic groups.

\section{Estimating Equations and Empirical Results}

The first estimating equation examines the determinants of the self-reported religion of respondents in the Afrobarometer surveys:

$$
\begin{aligned}
I_{i, e, v, c}^{R}= & \alpha_{c}+\beta M_{e}+\gamma M_{v}+\mathbf{X}_{i} \boldsymbol{\Gamma} \\
& +\mathbf{X}_{e} \boldsymbol{\Lambda}+\mathbf{X}_{v} \boldsymbol{\Phi}+\varepsilon_{i, e, v, c}
\end{aligned}
$$

where $i$ indexes individuals, $e$ ethnic groups, $v$ villages, and $c$ countries; $I^{R}$ is an indicator variable that equals one if individual $i$ self-identifies as being either a Catholic or Protestant (mainstream, Evangelical, or Pentecostal); $\alpha_{c}$ denotes country fixed effects; and $M_{e}$ measures the historic exposure of ethnic group $e$ to Christian missions.

The coefficient of interest, $\beta$, captures the relationship between historic exposure to missionaries and the religion of the respondent today. A positive coefficient provides evidence

\footnotetext{
${ }^{5}$ Space constraints prevent a full description of the data sources and the methods of construction of the control variables. Full details are provided in an online data Appendix which is available at: http://www.economics.harvard.edu/ faculty/nunn.
}

that missionaries changed the values and beliefs of those exposed to their teachings, and that these values and beliefs were then transmitted to future generations. To control for the effects of missions working through other channels that, unlike beliefs and norms, are geographically fixed and external to the individual, I also control for the location-specific measure of missionary activity, $M_{v}$. The variable is intended to capture any effects missions may have through public goods, physical capital, domestic institutions, and broader social structures, all of which are location-specific, rather than individual-specific.

$\mathbf{X}_{i}$ denotes a vector of individual-level control variables, which includes a gender indicator variable, age and age squared, occupation fixed effects, quality of living condition fixed effects, and an indicator variable that equals one if the respondent lives in an urban location. $\mathbf{X}_{e}$ denotes a vector of ethnicity-level control variables, including an indicator variable that equals one if early European explorers contacted the individual's ethnic group, an indicator variable equaling one if the ethnic group was connected to the colonial railway network, the fraction of the ethnic group's land suitable for cultivation, the fraction of land that is within ten kilometers of a water source, and a measure of the historic exposure of the ethnic group to the trans-Atlantic and Indian Ocean slave trades. $\mathbf{X}_{v}$ includes the same set of covariates, but measured at the village level.

Estimates of equation (1), using a logit model, are reported in Table 1. The first column reports coefficient estimates and clustered standard errors from a version of equation (1) that includes only the ethnicity-level mission variable, $M_{e}$, and the individual- and ethnicity-level control variables. Column 2 reports estimates from an equation that includes only the villagelevel mission variable, $M_{v}$, and the individualand village-level control variables. Estimates from column 3 are from the fully specified model reported as equation (1).

The estimates identify a strong, positive relationship between the likelihood that an individual identifies as being Christian today and his or her ancestors' proximity to mission stations during the colonial period. The results provide evidence that missionaries altered the beliefs and values of those exposed to their teachings, and that these beliefs were then passed on from 
Table 1-Mission Stations and Religious Conversion

\begin{tabular}{|c|c|c|c|c|c|c|}
\hline & \multicolumn{6}{|c|}{ Dependent variable: Protestant/Catholic indicator variable, $I_{i, e, v, c}^{R}$} \\
\hline & \multicolumn{3}{|c|}{ Full sample } & \multicolumn{3}{|c|}{ Non-Muslim sample } \\
\hline & (1) & $(2)$ & (3) & (4) & (5) & (6) \\
\hline Mission stations among ethnic group, $M_{e}$ & $\begin{array}{l}0.036^{* * * *} \\
(0.011)\end{array}$ & & $\begin{array}{l}0.144 * * * \\
(0.044)\end{array}$ & $\begin{array}{l}0.025^{* * *} \\
(0.011)\end{array}$ & & $\begin{array}{l}0.131 \text { **** } \\
(0.044)\end{array}$ \\
\hline Mission stations in village, $M_{v}$ & & $\begin{array}{l}0.021 * * * \\
(0.006)\end{array}$ & $\begin{array}{l}0.033^{* * * *} \\
(0.032)\end{array}$ & & $\begin{array}{l}0.083 \text { *** } \\
(0.032)\end{array}$ & $\begin{array}{c}0.070 \\
(0.044)\end{array}$ \\
\hline Individual-level controls & Yes & Yes & Yes & Yes & Yes & Yes \\
\hline Ethnicity-level controls & Yes & No & Yes & Yes & No & Yes \\
\hline Village-level controls & No & Yes & Yes & No & Yes & Yes \\
\hline Country fixed effects & Yes & Yes & Yes & Yes & Yes & Yes \\
\hline Observations & 20,755 & 20,755 & 20,755 & 7,969 & 7,969 & 7,969 \\
\hline Clusters & 185 & 2,693 & $185 / 2,693$ & 70 & 1,160 & $70 / 1,160$ \\
\hline Pseudo $R^{2}$ & 0.28 & 0.28 & 0.29 & 0.31 & 0.32 & 0.32 \\
\hline
\end{tabular}

Notes: The table reports logit estimates where the unit of observation is an individual. Coefficients are reported, with clustered standard errors in brackets. All regressions include country fixed effects. Individual-level controls include age, age squared, a gender indicator variable, five living condition fixed effects, 25 occupation fixed effects, and an indicator for whether the respondent lives in an urban location. Ethnicity-level controls include an indicator variable that equals one if the ethnicity was contacted by a European explorer prior to the colonial period, an indicator variable that equals one if a railway line dissected the land inhabited by the ethnicity during the nineteenth century, a measure of the fraction of land suitable for cultivation and the fraction of land within ten kilometers of a water source, and the log normalized number of slaves exported during the Atlantic and Indian Ocean slave trades. The village-level controls include the same set of control variables, but measured at the village level.

*** Significant at the 1 percent level.

** Significant at the 5 percent level.

* Significant at the 10 percent level.

parents to children, up until the present day. The positive and significant coefficient for $M_{v}$ provides evidence for an influence of mission stations working through geographically fixed factors. However, comparing the strength of the two channels, one finds that the ethnicity-level mechanism (i.e., transmitted beliefs and values) is seven times greater than the location-specific mechanism. ${ }^{\mathbb{6}}$ In other words, what matters most for an individual's religious beliefs today is the exposure of their ancestors to missionary activity, not the intensity of missionary activity in the village where they currently live.

One concern with the estimates is that they may simply reflect the ethnic and geographic sorting of Christians and Muslims within

\footnotetext{
${ }^{6}$ The standard deviation of $M_{e}$ is 2.25 and of $M_{v}$ is 1.39 . A one standard deviation increase in $M_{e}$ increases the chance of the respondent being Christian by 0.32 or 32 percentage points, and a one standard deviation increase in $M_{v}$ increases the probability by 0.046 or 4.6 percentage points. The mean of the dependent variable is 0.58 or 58 percent.
}

certain countries in the sample. In the parts of Sub-Saharan Africa where Islam existed, missionaries were less likely to establish missionary stations. Since the ethnic groups in these areas, continue to be predominantly Muslim today, this may induce a spurious relationship between historic missionary activity and Christianity today. To address this concern, I omit from the sample the ten countries with a Muslim population share greater than two percent. Estimates using this more restricted sample are reported in columns 4-6 of Table 1. The results are highly robust. The estimated coefficients are remarkably similar, and the coefficient of interest, $\beta$, remains negative and highly significant, providing added evidence of the long-run effect of missionaries on religious beliefs.

I now turn to estimates of the potential impacts of the translation and distribution of the Bible on long-run religious conversion. I do this for two reasons. The first reason is motivated by historical interest, and the second is because the estimates provide a gauge of the extent to which 
the endogenous location of missionary activities may be biasing the estimates of equation (1).

One of the initial strategies of missionaries was to simply expose Africans to the word of God by providing them access to the Bible. It soon became apparent that this strategy was ineffective; the word of God just wasn't enough. The 1907 address by Leslie Probyn, Governor of Sierra Leone, describes the problems with the strategy. "It is thought by some that they [Africans] are always open to absorb what is good readily; that all you have to do if you want to make Christians is to export so many cases of Bibles, and on distributing the latter you obtain, with the quickness of a conjuring trick, a corresponding number of devout Christians. That is what is expected by many of the contributors to mission societies. It is not so." He continues to state that Africans "are a very cautious race, and they will not accept new ideas merely because they are presented to him by a white man ... missionary work does not simply consist in distributing Bibles." (Probyn 1907, 252253). Missionaries soon realized that Africans were most successfully converted when along with conversion came benefits, most notably Western education, but also health care and other forms of training (Edward H. Berman 1974). These benefits, rather than the word of God alone, were the most effective means of conversion.

From an econometric viewpoint, the existence of a benign missionary activity provides a potential falsification test that can be used to assess the strength of selection effects in the data. If exposure to the Bible translated into the vernacular, or being close to a Bible depot, had no effect on conversion (as the historical record suggests), but there are strong selection effects, then we expect to find a strong positive relationship between exposure to the Bible and long-term conversion. If selection effects are not present, then we expect no such relationship. To examine this, I estimate the following equation:

$$
\text { (2) } \begin{aligned}
\mathrm{I}_{i, e, v, c}^{R}= & \alpha_{c}+\delta B F B S_{e}+\gamma B F B S_{v}+\eta I_{e}^{B} \\
& +\lambda I_{e}^{N B}+\mathbf{X}_{i} \boldsymbol{\Gamma}+\mathbf{X}_{e} \boldsymbol{\Lambda}+\mathbf{X}_{v} \boldsymbol{\Phi} \\
& +\varepsilon_{i, e, v, c}
\end{aligned}
$$

All control variables are identical to equation (1), except now $\mathbf{X}_{e}$ and $\mathbf{X}_{v}$ also include $M_{e}$ and $M_{v}$. (The results are the same with or without these additional control variables.) $I_{e}^{B}$ and $I_{e}^{N B}$ are indicator variables that equal one if the Bible was translated (and not translated, respectively) into the language of ethnic group $e$. The omitted category is for languages for which we do not have evidence to support or disprove translation. $B F B S_{e}$ and $B F B S_{v}$ measure the number of British and Foreign Bible Society (BFBS) Bible depots located among ethnic group $e$ and in village $v$. These are constructed in the same manner as $M_{e}$ and $M_{v}$.

Estimates of equation (2) are reported in Table 2. The results fail to provide evidence for a relationship between increased exposure to the Bible and conversion. The indicator variable for the translation of the Bible into an ethnicity's vernacular is actually negatively correlated with conversion to Christianity, not positively as one would expect. There is weak evidence of a positive relationship between historical exposure to Bible depots and conversion. However, one coefficient is insignificant and the other is only marginally significant.

Overall, the findings in Table 2 are consistent with two hypotheses being true. First, consistent with the historical record, merely exposing Africans to the word of God was not sufficient for conversion. Instead, additional benefits, which were provided through mission stations, were needed to entice Africans to convert to Christianity. Second, the results are also consistent with the absence of a strong selection bias. There is no evidence that missionary efforts were targeted to ethnic groups with the greatest potential to convert for reasons other than missionary influence. This provides greater confidence that the correlations identified in Table 1 are close to the true causal effect of missionary activity on long-term religious beliefs.

\section{Conclusions}

I have presented empirical evidence showing how historic events can have long-term impacts on culture. The results show that the descendants of those exposed to European missionaries are today more likely to self-identify as being Christian. This is evidence that missionaries altered the religious beliefs and values 
Table 2-Exposure to the Bible and Religious Conversion

\begin{tabular}{|c|c|c|c|c|}
\hline & \multicolumn{4}{|c|}{ Dependent variable: Protestant/Catholic indicator variable, $I_{i, e, v, c}^{R}$} \\
\hline & (1) & (2) & (3) & (4) \\
\hline Bible translated into language of ethnic group, $I_{e}^{B}$ & $\begin{array}{c}-0.127 * * \\
(0.051)\end{array}$ & & & $\begin{array}{c}-0.348^{*} \\
(0.208)\end{array}$ \\
\hline Bible not translated into language of ethnic group, $I_{e}^{N B}$ & $\begin{array}{c}0.020 \\
(0.044)\end{array}$ & & & $\begin{array}{c}0.163 \\
(0.174)\end{array}$ \\
\hline Bible depots among ethnic group, $B F B S_{e}$ & & $\begin{array}{c}0.021 \\
(0.014)\end{array}$ & & $\begin{array}{c}0.130 * \\
(0.076)\end{array}$ \\
\hline Bible depots in village, $B F B S_{v}$ & & & $\begin{array}{c}0.022 \\
(0.032)\end{array}$ & $\begin{array}{r}-0.052 \\
(0.155)\end{array}$ \\
\hline Individual-level controls & Yes & Yes & Yes & Yes \\
\hline Ethnicity-level controls & Yes & Yes & No & Yes \\
\hline Village-level controls & No & No & Yes & Yes \\
\hline Country fixed effects & Yes & Yes & Yes & Yes \\
\hline Observations & 20,755 & 20,755 & 20,755 & 20,755 \\
\hline Clusters & 185 & 185 & 2,693 & $185 / 2,693$ \\
\hline Pseudo $R^{2}$ & 0.29 & 0.28 & 0.29 & 0.29 \\
\hline
\end{tabular}

Notes: The table reports logit estimates where the unit of observation is an individual. Coefficients are reported, with clustered standard errors in brackets. All regressions include country fixed effects. Individual-level controls include age, age squared, a gender indicator variable, five living condition fixed effects, 25 occupation fixed effects, and an indicator for whether the respondent lives in an urban location. Ethnicity-level controls include an indicator variable that equals one if the ethnicity was contacted by a European explorer prior to the colonial period, an indicator variable that equals one if the railway line dissected the land inhabited by the ethnicity during the nineteenth century, a measure of the fraction of land suitable for cultivation and the fraction of land within ten kilometers of a water source, and the log normalized number of slaves exported during the Atlantic and Indian Ocean slave trades, and the log number of missions normalized by land area. The village-level controls include the same set of control variables, but measured at the village level.

***Significant at the 1 percent level.

**Significant at the 5 percent level.

* Significant at the 10 percent level.

of those they were in contact with, and these beliefs were then transmitted from parents to children until today. The findings provide one example of the historical origins of cultural differences.

\section{REFERENCES}

Barro, Robert J., and Jason Hwang. 2007. "Religious Conversion in 40 Countries." National Bureau of Economic Research Working Paper 13689.

-Berman, Edward H. 1974. "African Responses to Christian Mission Education.” African Studies Review, 17(3): 527-40.

Guiso, Luigi, Paola Sapienza, and Luigi Zingales. 2007. "Long Term Persistence." Unpublished.

-Iyigun, Murat. 2008. "Luther and Suleyman."
Quarterly Journal of Economics, 123(4): 1465-94.

-Johnson, Hildegard Binder. 1967. "The Location of Christian Missions in Africa." Geographical Review, 57 (2): 168-202.

Murdock, George Peter. 1959. Africa: Its Peoples and Their Culture History. New York: McGraw Hill.

Nunn, Nathan, and Leonard Wantchekon. 2009. "The Slave Trade and the Origins of Mistrust in Africa." Unpublished.

Probyn, Leslie. 1907. "Sierra Leone and the Natives of West Africa." African Affairs, 6(23): $250-8$.

Woodberry, Robert D. 2004. "The Shadow of Empire: Christian Missions, Colonial Policy, and Democracy in Post Colonial Societies." $\mathrm{PhD}$ diss. University of North Carolina at Chapel Hill. 